\title{
Performance comparison between PWM and MPPT charge controllers
}

\author{
Comparación del desempeño entre un controlador de carga PWM y un controlador MPPT
}

\author{
M. A. Laguado-Serrano , E. A. Luna-Paipa , L. F. Bustos-Marquez iD , S. B. Sepulveda-Mora iD
}

\begin{abstract}
Charge controllers are implemented in several electronic systems to protect and control the charge and discharge rates of a battery; for off-grid Photovoltaic (PV) systems, there are two types of technologies, Pulse Width Modulation (PWM) and Maximum Power Point Tracking (MPPT). In this work, we compared two charge controllers in PV systems with the same technical specifications in order to determine the behavior of each of them under similar environmental conditions. The implementation of both charge controllers was based on firmware and hardware with original designs, using PWM and MPPT technologies. Both PV systems are composed of the charge controller, a $30 \mathrm{~W}$ solar panel and a $12 \mathrm{~V}-18$ Ah battery; in the experimental tests we measured the voltage and current in the panel and the battery in charge and discharge processes, observing that the MPPT controller has a higher average efficiency than the PWM controller, elucidating that the type of technology used in the charge controller has a direct impact on the efficiency, even under unfavorable conditions of solar radiation and environmental temperature. The PWM controller is an option of acceptable efficiency and lower price in relation to the MPPT controller. In the implementation of both controllers we calculated similar periods of autonomy.
\end{abstract}

Index Terms-Charge controller, Maximum Power Point Tracking, Micro-controller, Off-grid PV Systems, Pulse Width Modulation.

Resumen - Los controladores de carga son implementados en varios sistemas electrónicos con el objetivo de proteger y controlar la carga y descarga de una batería; en el caso de los controladores utilizados en sistemas fotovoltaicos autónomos se implementan dos tipos de tecnologías, Pulse Width Modulation (PWM) y Maximum Power Point Tracking (MPPT). En este artículo se compararon dos controladores de carga con diseños originales en sistemas fotovoltaicos con las mismas especificaciones técnicas para determinar el comportamiento de cada uno bajo condiciones ambientales similares. La implementación de ambos controladores de carga se basó en software y hardware con diseños originales, utilizando tecnología PWM y MPPT. Ambos sistemas están compuestos por el controlador de carga, un panel solar de $30 \mathrm{~W}$ y una batería de $12 \mathrm{~V}$ a $18 \mathrm{Ah}$; se realizaron las pruebas experimentales de ambos controladores midiendo voltaje $y$ corriente en el panel $y$ en la batería en procesos de carga y

This manuscript was sent on January 25, 2019 and accepted on March 15, 2019.

M. A Laguado - Serrano is with Francisco de Paula Santander University Universit.(email: miguelangells@ufps.edu.co).

E. A. Luna Paipa is with Francisco de Paula Santander University University (email: eduardoandreslp@ufps.edu.co). descarga, observando que el controlador MPPT tiene una eficiencia promedio mayor que el controlador PWM debido a que el tipo de tecnología implementada influye directamente en la eficiencia, incluso ante valores menos favorables de radiación solar y temperatura ambiente. El controlador PWM es una opción de eficiencia aceptable y además de bajo costo respecto al controlador MPPT. En la implementación de ambos controladores se calcularon tiempos de autonomía similares.

Palabras claves - Controlador de carga, Microcontrolador, Modulación por ancho de pulsos, Seguidor de Punto de Máxima Potencia, Sistema Fotovoltaico Autónomo.

\section{INTRODUCTION}

$\mathrm{T}$ he renewable energy sources represent a clean and reliable alternative [1]; these could be implemented gradually to reduce the contamination produced by energy sources based on fossil fuels [2]. Among these the photovoltaic solar energy stands out which is a form of electric energy production that harvests the solar radiation [3], therefore, it allows to reach rural zones where there is not possibility of delivering conventional electric energy. The photovoltaic systems can be classified in two kinds, the Grid-tied and the Off-grid [6], the first are systems connected to the conventional electric energy grid and the second are autonomous systems. The architecture of the Off-grid photovoltaic systems is formed by an arrangement of solar panels, a battery bank, a charge controller, and if the loads to power are $\mathrm{AC}$ (alternating current), the system includes a DC/AC inverter.

One of the most influential elements on the quality and lifespan of the system is the charge controller [7], due to its functions of protecting the battery from overcharges and deep discharges [8]. The charge controller can also extract the maximum power from the solar panel to deliver it to the load, based on its characteristics.

The PWM [9] and MPPT [10] charge controllers are the two most common types; the main goal of this paper is to determine which of the two types of controllers offers the best cost-benefit relation under similar environmental conditions. The two photovoltaic systems implemented in this work are original

L. F. Bustos - Márquez is with Francisco de Paula Santander University (email: luisfernandobm@ufps.edu.co)

S. B. Sepulveda - Mora is with Francisco de Paula Santander University (email: sergio.sepulveda@ufps.edu.co) 
designs with the same technical characteristics on their architecture, which consist of a solar panel of $30 \mathrm{~W}$ and a lead acid Absorbent Glass Mat (AGM) battery with $12 \mathrm{~V}$ of nominal voltage and capacity of $18 \mathrm{Ah}$. In both systems, we measured the voltage and current on the solar panel and the battery, the environment temperature around the solar panel and the solar incident radiation in order to compare the efficiency of the photovoltaic systems during the same sampling time on the charge and discharge processes of the battery. Additionally, both systems implement the open circuit voltage method along with the ampere-hour counting algorithm to estimate the state of charge of the battery [11].

The charging algorithm of the AGM battery is based on three stages: the first one is Bulk or charging at constant current, when the charge controller provides all the possible current to the battery until it reaches $80 \%$ of its capacity. Next is absorption stage, or controlled overcharge, when the controller keeps a constant voltage and the value of the current gradually lowers as the battery completes its charging process. At last, the float stage is where the battery has been charged at $100 \%$.

Analyzing the data that was obtained from the comparison between both photovoltaic systems, the MPPT controller proved to be more efficient than the PWM controller in prolonged times of operation. We also found out that the environment conditions do not influence the efficiency of the charge controllers. However, from the comparison between both controllers we determined the conditions under which a PWM controller can be implemented instead of an MPPT controller trading off efficiency for savings in the cost.

\section{MATERIALS AND METHODS}

In order to perform a comparison of the performance between an MPPT charge controller and a PWM controller, we used two photovoltaic systems with the same technical specifications. On both systems, a polycrystalline solar panel was used with a power of $30 \mathrm{~W}$, and a maximum power point of $18 \mathrm{~V}(\mathrm{Vmp})$ and $1.667 \mathrm{~A}$ (Imp). As for the battery, both systems used an acid lead AGM battery with a nominal voltage of $12 \mathrm{~V}$, and a capacity of 18 Ah from Magna manufacturer. For the MPPT controller a $6 \mathrm{~W}$ DC lamp was used as a load; however, since the PWM controller, unlike the MPPT controller, cannot deliver the maximum power from the solar panel to turn on the lamp, a $4 \mathrm{~W}$ DC lamp was used as the load for the PWM controller.

\section{B. Implementation of the PWM controller}

The electronic circuit of the designed PWM controller is composed of a control sub-circuit and a power sub-circuit. The main component of the control sub-circuit is the PIC $16 \mathrm{~F} 877$ micro-controller, which receives voltage signals coming from the voltage and current sensors of the system. The microcontroller processes this data and modifies the duty cycle of two PWM signals, one to control the current flow from the panel to the battery and the other signal to control the current flow from the battery to the connected load. The voltage sensors are voltage dividers that measure the voltage of the panel and the battery. The current flowing to the battery and the current delivered by the battery were both measured with a bidirectional Hall Effect ACS712 current sensor.

On the other hand, the power sub-circuit consists of two Metal oxide Semiconductor Field-effect transistors (MOSFET), which perform the switching of the connections between the solar panel, the battery, and the load. The on and off switching performed by the MOSFETs is synchronized to the PWM signals generated by the micro-controller. In order to generate the trigger voltage for the MOSFETs, two stages of amplification were implemented using Bipolar Junction Transistors (BJT); the output voltages of these amplification stages are fed to the Gate and Source terminals of the MOSFETs.

For the calculation of the efficiency on both charge controllers, the voltage and current variables of the battery and the solar panel were considered as established in equation (1).

$$
\operatorname{Efficiency}(\%)=\frac{V_{\text {Bat }} \times I_{\text {Bat }}}{V_{\text {Panel }} * I_{\text {Panel }}} \times 100
$$

Where:

$V_{B a t}$ : Voltage measured on the battery in volts (V)

$I_{B a t}$ : Current measured on the positive line of the battery in amperes (A)

$V_{\text {Panel: }}$ Voltage measured on the solar panel in volts (V)

$I_{\text {Panel }}$ : Current measured on the solar panel output in amperes (A)

The efficiency of the PWM charge controller was calculated by taking voltage and current data from the solar panel and the battery while the controller was operating during 5 continuous hours. We repeated this measuring process for 4 consecutive days to check the transition of the charging stages and to test the behavior of the controller under normal operation conditions. Additionally, the ambient temperature surrounding the solar panel was measured using the thermocouple of the UNIT-UT33C digital multimeter; the incident solar radiation on the panel was also measured using an SP-110 pyranometer from Apogee Instruments. The tests were performed with ambient temperatures above $35^{\circ} \mathrm{C}$. After measuring the different variables during the implementation of the PWM controller, the average efficiency was calculated. Fig. 1 displays the efficiency of the PWM charge controller versus the elapsed time of the experiments. 


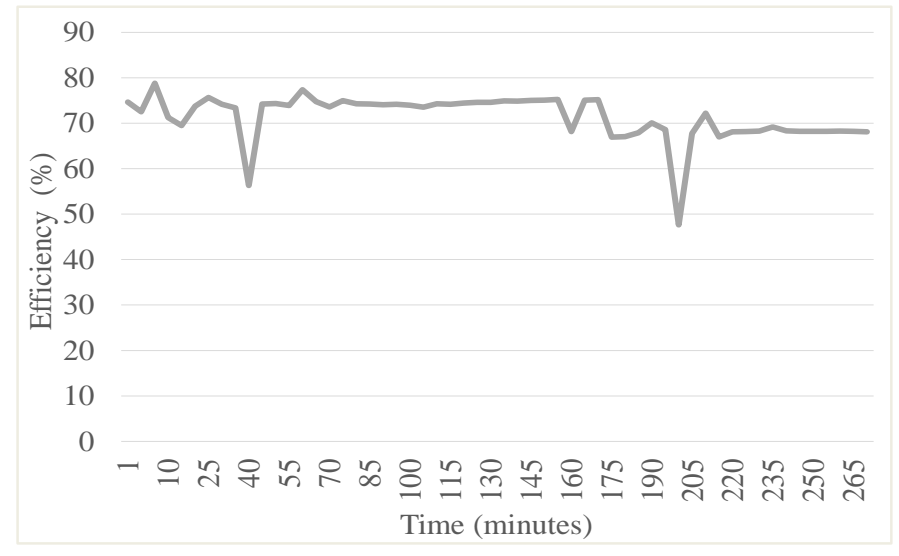

Fig. 1. Efficiency of the PWM charge controller versus time.

\section{Implementation of the MPPT controller}

This controller is composed, in a similar way to the PWM, of two sub-circuits: one for the control functions and the other one to supply the required power. Regarding the control sub-circuit, a PIC16F887 micro-controller is in charge of the interpretation an evaluation of variables, the operation of algorithms, and the control of the human-machine interface. A modified capacitorless DC/DC buck converter constitutes the power sub-circuit; the converter allows the interaction between the solar panel, the battery, and the load.

In this controller, the Perturbation and Observation algorithm $(\mathrm{P} \& \mathrm{O})$ was implemented. It consists of varying the duty cycle of the converter altering the power delivered by the solar panel. The algorithm evaluates if the variation in the voltage of the converter produces an increment or a decrement in the power of the solar panel, then it varies the duty cycle and hence the voltage of the converter accordingly searching for the maximum energy from the solar panel. For this control, it was necessary to implement voltage and current sensors in the input and output of the charge controller. Bidirectional ACS712 Hall Effect sensors were used to measure the currents, while the voltage measurements were realized with voltage dividers.

In order to generate the trigger voltage of the DC/DC converter, we used an IRF2110 driver which generates the floating source needed for the MOSFET activation through a Bootstrap circuit. However, for the connection and disconnection of the battery and the load, we used low triggering voltage $(2 \mathrm{~V} \sim 4 \mathrm{~V})$ MOSFET switches connected to ground, which allowed their triggering through signals that were coming from the microcontroller.

Similar to the previous experiment described in section B, we measured the voltage and current from the solar panel and the battery, the ambient temperature, and the solar radiation. Then, the efficiency of the MPPT charge controller was determined using equation (1). During the experiment, the proposed charge and discharge algorithms, the charging stages, and the performance of the controller were verified. The tests were made under similar environmental characteristics to the ones in the PWM controller experiments, with temperatures above $35{ }^{\circ} \mathrm{C}$ and solar radiation above $700 \mathrm{~W} / \mathrm{m}^{2}$. The efficiency of the MPPT controller versus the elapsed time during the tests is presented in Fig. 2.

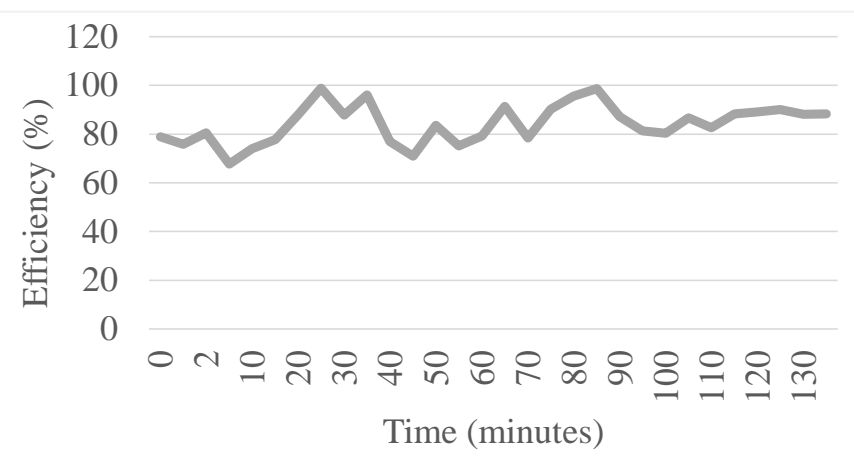

Fig. 2. Efficiency of the MPPT controller versus time.

\section{RESULTS}

The comparison between the MPPT and the PWM controllers was made considering the efficiency of both versus the average incident solar radiation and the ambient temperature surrounding the photovoltaic systems. In the MPPT controller experiment, the average incident solar radiation was 743.86 W/m $\mathrm{m}^{2}$ with an average ambient temperature of $41.9^{\circ} \mathrm{C}$. On the other hand, in the PWM controller experiment, the average incident solar radiation was $812.95 \mathrm{~W} / \mathrm{m}^{2}$ with an average ambient temperature of $39.35^{\circ} \mathrm{C}$ (see Table I).

TABLE I.

EFFICIENCY OF THE CHARge CONTROLLERS VERSUS THE AVERAGE RADIATION AND TEMPERATURE.

\begin{tabular}{llll}
\hline \hline Controller & $\begin{array}{l}\text { Temperature } \\
\left({ }^{\circ} \mathrm{C}\right)\end{array}$ & $\begin{array}{l}\text { Radiation } \\
\left(\mathrm{W} / \mathrm{m}^{2}\right)\end{array}$ & $\begin{array}{l}\text { Efficiency } \\
(\%)\end{array}$ \\
\hline PWM & 39.35 & 812.95 & 71.42 \\
$M P P T$ & 41.9 & 743.86 & 86.82 \\
\hline \hline
\end{tabular}

The data measured on both charge controllers were not taken simultaneously, but the experiments were performed under similar environmental conditions. As it can be seen in Table I, there is only a $6.48 \%$ difference in the temperature and an $8.49 \%$ difference in the radiation during the tests performed on both charge controllers. The MPPT controller efficiency exceeded the PWM controller efficiency by $15.4 \%$, despite of the slightly better environmental conditions presented on the experiment of the PWM controller. Regarding the charging processes, Fig. 3 shows the comparison between the voltage variation on the battery in both controllers, while Fig. 4 depicts the comparison between the variation of the current delivered by the charge controllers to the battery. 


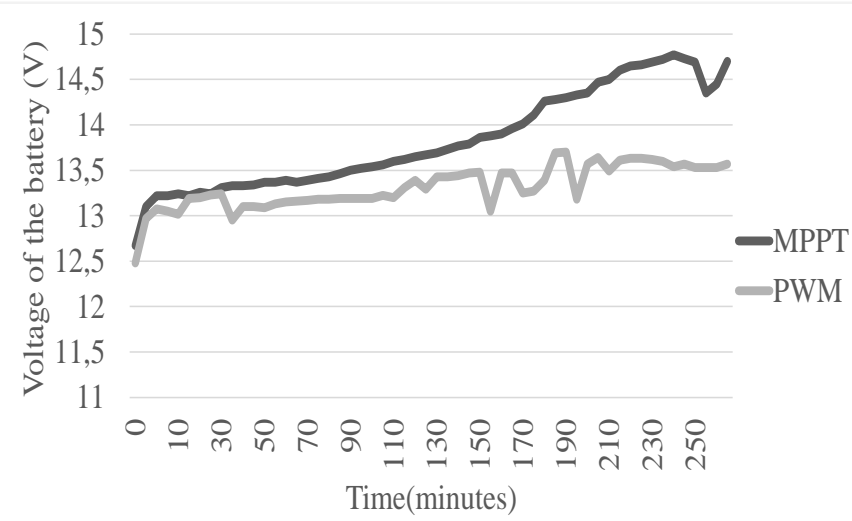

Fig. 3. Comparison of voltage on the battery versus time in the charging process.

As seen in Fig. 3, during the operation of the MPPT controller, the first 200 minutes correspond to the Bulk stage of the charging process, where the battery voltage increases linearly until it reaches approximately $14.7 \mathrm{~V}$. After that, the controller maintains this voltage value, this corresponds to the Absorption stage. Finally, after 250 minutes, the voltage decreases drastically, due to the action of the controller to reduce the current delivered to the battery in order to maintain the voltage below the floating value. In the PWM case, during the first 215 minutes the controller was in the Bulk stage increasing the battery voltage; once it gets to the absorption stage, the controller maintains the voltage in $13.7 \mathrm{~V}$ approximately. The MPPT controller delivers more current from the solar panel to the battery and that is why the voltage increases more on the Bulk stage compared to the PWM controller.

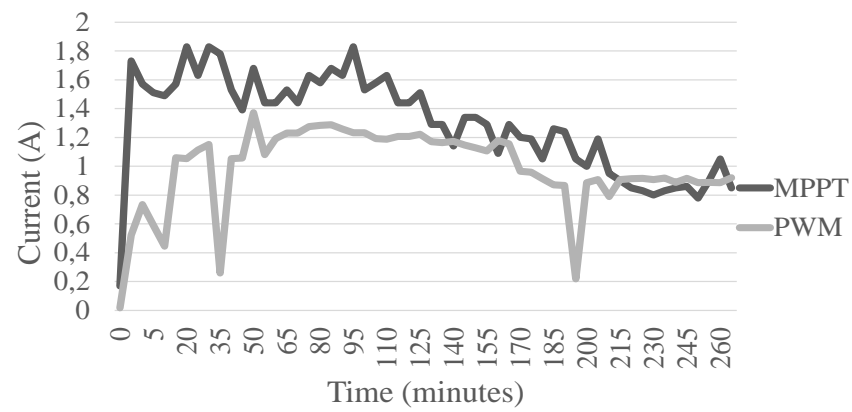

Fig. 4. Comparison of the current delivered to the battery versus time in the charging process.

Referring to Fig 4, the current delivered by the MPPT controller surpasses the value of $1 \mathrm{~A}$ reaching up to $1.8 \mathrm{~A}$ during the first 200 minutes, meaning that the controller is in the Bulk stage; once the controller begins to operate in the absorption stage, the current decreases to values below $1 \mathrm{~A}$. In the PWM controller case, the current increases to values near 1.2 A during the first 215 minutes when it is operating in the Bulk stage and once it reaches the absorption stage the current slightly decreases. In the minutes 35 and 195 the current delivered to the battery decreases drastically, this is because when these measures were made, the incident solar radiation decreased below $300 \mathrm{~W} / \mathrm{m}^{2}$, which is why the solar panel delivered lower currents, and the technology used by the PWM controller cannot maximize power generated by the panel.

For the discharging process, we compared the decrease of the battery voltage versus time for both controllers as shown in Fig. 5. The variation of the current delivered to the load was also compared, and it can be observed in Fig. 6. It is worth to mention that in the discharge tests for the MPPT controller, a DC load of $6 \mathrm{~W}$ was used, while in the discharge tests for the PWM controller a DC load of $4 \mathrm{~W}$ was used.

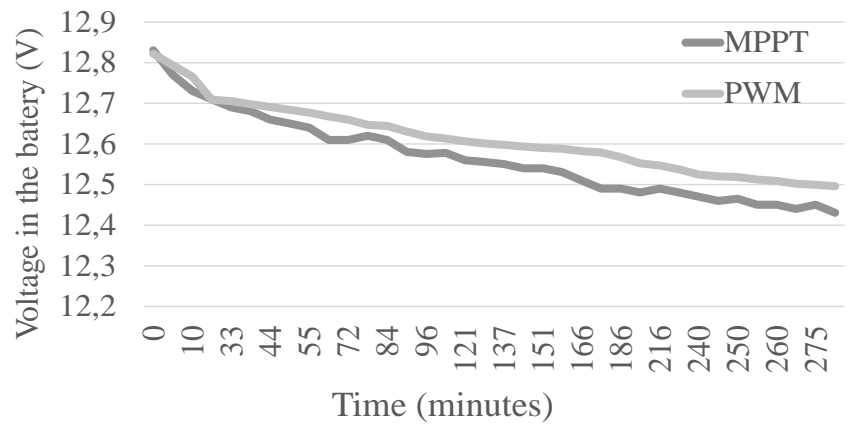

Fig. 5. Comparison of voltage in the battery versus time in the discharging process.

In the discharging process both batteries started with a voltage value of $12.8 \mathrm{~V}$ and over the course of 275 minutes, the voltage of the battery implementing the MPPT controller decreased to $12.43 \mathrm{~V}$ and in the case of the PWM controller the voltage in the battery decreased to $12.49 \mathrm{~V}$. The small variation is due to the $2 \mathrm{~W}$ difference between the loads connected to each controller. However, the decreasing behavior of the voltage in time was similar in both cases.

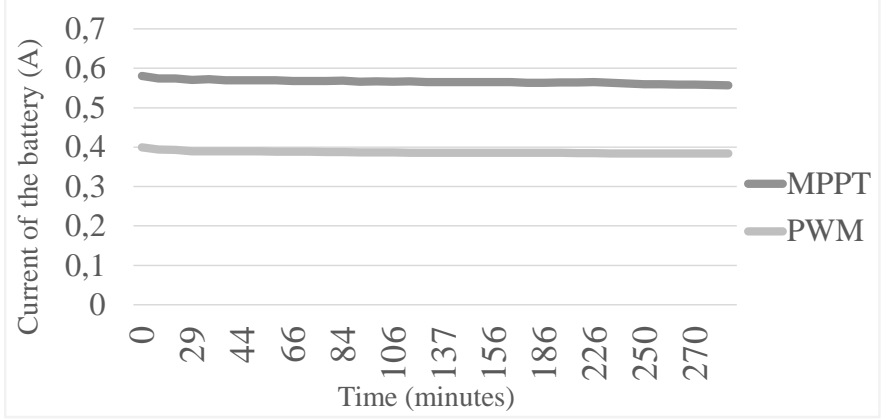

Fig. 6. Comparison of current delivered from the battery to the load versus time in the discharging process.

Regarding the behavior of the current delivered to the load in the discharging process of the battery, a similar decreasing profile was evidenced for both controllers. The difference between the current levels is due to fact that the power of the load connected to the MPPT controller was greater than the one used with the PWM controller. In both cases, the current delivered from the battery to the load was approximately constant over time, with a decrease of only $24 \mathrm{~mA}$ in the case of the MPPT controller and a current reduction of $16 \mathrm{~mA}$ for the PWM controller. 


\section{CONCLUSIONS}

The average efficiency of the MPPT controller was $14.9 \%$ higher than the PWM controller, despite the fact that on the tests of the PWM controller the environmental conditions were more favorable, such as a lower ambient temperature meaning a lower temperature in the cells of the solar panel, and an average solar radiation of $70 \mathrm{~W} / \mathrm{m}^{2}$ higher. Accordingly, it can be affirmed that the type of technology implemented on a charge controller affects the efficiency on the power transference from the solar panel to the battery in a greater way than the incident solar radiation or the ambient temperature does.

In the charging process of the battery, the voltage in the MPPT charge controller increases at a more accelerated pace than it does in the PWM charge controller, reaching a maximum value of $14.7 \mathrm{~V}$ when the PWM reaches a maximum value of $13.7 \mathrm{~V}$. On the other hand, an increase of the current delivered to the battery in both systems was observed, reaching a maximum point of $1.8 \mathrm{~A}$ for the MPPT and 1.4 A for the PWM. Then, after 200 minutes both values start to match each other until they reach a point where both systems deliver an approximate value of $0.9 \mathrm{~A}$ of current to the battery, because after 200 minutes the MPPT controller enters to the absorption stage, and in the case of the PWM controller, it enters to the same stage after 215 minutes.

During the discharging process, the voltages decreased at a similar and constant pace for both controllers, while the current behavior was approximately constant with tiny decrements for each case.

The MPPT charge controller had a higher average efficiency and superior performance compared to the PWM charge controller, considering the conditions under which the tests were realized in the city of Cúcuta, Colombia. However, the PWM charge controller offers an option of acceptable efficiency as well as low-cost versus the MPPT controller. Based on the cost analysis made on both controllers using wholesale prices of each electronic component, accounting for profits and assembling costs, we calculated a commercial price of \$ 59.300 COP for the PWM controller and \$ 166.500 COP for the MPPT controller. Consequently, the PWM charge controller is a viable option for those users who wish to implement a reliable, efficient and low-cost controller, obtaining savings of $\$ 107.200$ for a $15.4 \%$ lower efficiency compared to the MPPT controller.

\section{REFERENCES}

[1] T. Peterson and C. Horton, "Communicating about Solar Energy and Climate Change", Oxford Research Encyclopedia of Climate Science, pp. 1-48, 2017. DOI: 10.1093 /acrefore/9780190228620.013.437

[2] K. Bos, and J.Gupta J, "Climate change: the risks of stranded fossil fuel assets and resources to the developing world", Third World Quarterly, pp. 1-18, 2017. DOI: $10.1080 / 01436597.2017 .1387477$

[3] R. Nasrin, and N. Hasanuzzaman, "Effect of high irradiation on photovoltaic power and energy", International Journal of Energy Research, 2017.

DOI: $\underline{10.1002 / \mathrm{er} .3907}$
[4] R. Thapa, "Off-Grid Energy an Option for Rural Energy Solution", Imperial Journal of Interdisciplinary Research, vol. 3, pp. 1064-1070, 2017.

[5] A. Escobar, C. Torres, and R. Hincapie, "Conexión de un sistema fotovoltaico a la red eléctrica", Scientia Et Technica, vol. XV, nº 43, pp. 31-36, 2009 DOI: $10.22517 / 23447214.1751$

[6] A. Gaga, O. Diouri, N. Es-sbai, and F. Errahimi, "Design and realization of an autonomous solar system", IOP Conference Series: Materials Science and Engineering, pp. 1-10, 2017. DOI: 10.1088/1757-899X/186/1/012031

[7] D. Hoyos, "Análisis, diseño y construcción de un controlador fotovoltaico", Publicación de Avances en Energías Renovables y Medio Ambiente, vol. 9, pp. 1-6, 2005.

[8] Y. Yang, Y. Qing, L. Tung, M. Greenleaf, and L. Hui, "Integrated Size and Energy Management Design of Battery Storage to Enhance Grid Integration of Large-scale PV Power Plants", IEEE Transactions on industrial electronics, 2017. DOI: 10.1109/TIE.2017.2721878

[9] J. Chang, H. Liahng, and C. Yi Hung, "Solar power generation system for reducing leakage current", International Journal of Electronics, pp. 1-15, 2017.

DOI: $10.1080 / 00207217.2017 .1382010$

[10] I. Elzein, "An Evaluation of Photovoltaic Systems MPPT Techniques under the Characteristics of Operational Conditions", Journal of the American Society for Information Science, vol. 2, n 2, pp. 30-38, 2017.

[11] S. Piller, M. Perrin, and A. Jossen, "Methods for state-of-charge determination and their applications", Journal of Power Sources, pp. 113-120, 2001.

DOI: $10.1016 / \mathrm{S} 0378-7753(01) 00560-2$

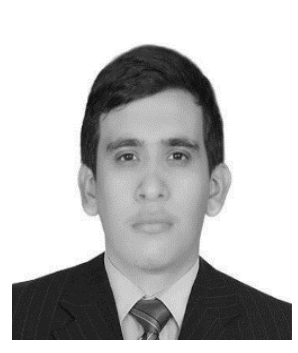

Miguel Angel Laguado Serrano was born in Cucuta, Norte de Santander, Colombia, in 1995. He received his bachelor's degree in Electronics Engineering from Francisco de Paula Santander University, Cucuta, Colombia in 2017. From 2016 to 2017 he was a member of the Applied Microelectronics research group (GIDMA) in Francisco de Paula Santander University and IEEE student member from 2017 to 2018. Since 2018 he is a teacher in Los Proceres School acting as head of the Math area and advisor of projects in Applied Physics. His research interests include photovoltaic solar energy, microelectronics, and power electronics.

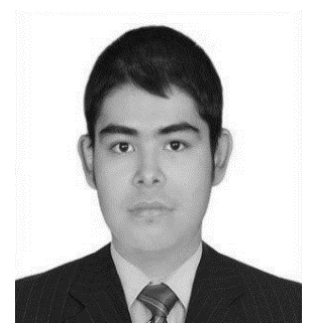

Eduardo Andres Luna Paipa was born in Cucuta, Colombia in 1995. He received the bachelor's degree in Electronics Engineering from Francisco de Paula Santander University, Cucuta, Colombia, in 2017. He was a member of the Applied Microelectronics research group (GIDMA) in Francisco de Paula Santander University from 2016 to 2017. His research interests are photovoltaic solar energy, microelectronics, and power electronics. 


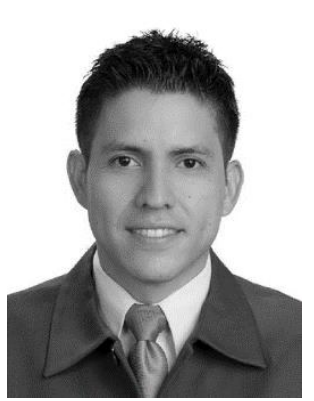

Sergio Basilio Sepúlveda Mora (M'13) was born in Cucuta, Colombia in 1984. He received a bachelor's degree in Electronics Engineering in 2007 from Francisco de Paula Santander University in Cucuta, Colombia. He received his Master of Science in Electrical and Computer Engineering in 2012 from University of Delaware, Newark, DE, USA. $\mathrm{He}$ is currently pursuing a $\mathrm{PhD}$ in Electrical Engineering at the Institute of Energy Conversion from University of Delaware.

$\mathrm{He}$ is a faculty member in the Department of Electricity \& Electronics at Francisco de Paula Santander since 2009, where he is also a member of the Applied Microelectronics (GIDMA) and Telecommunications (GIDET) Research groups. He is an IEEE Professional member since 2013 and advisor of the Power and Energy Society IEEE student branch at Francisco de Paula Santander University. His research interests include photovoltaic solar energy, microelectronics, wireless sensor networks, data science, and machine learning.

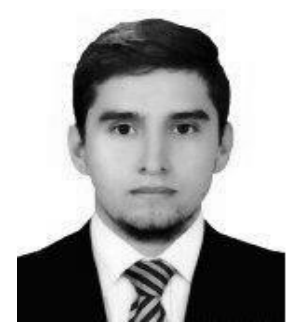

Luis Fernando Bustos Márquez (M'13) was born in Cucuta, Colombia in 1994. He received the bachelor's degree in Electronics Engineering and the Specialist degree in Pedagogical Practice in 2016 and 2018 respectively, from Francisco de Paula Santander University in Cucuta, Colombia.

He has worked as an engineer and researcher in the areas of data science, solar energy, energy demand and energy efficiency in the Sustainable Rural Energization Plan (PERS) for Norte de Santander, developed by Francisco de Paula Santander University, the Unit of Mining-Energy Planning (UPME) and the Institute of Planning and Promotion of Energy Solutions for Non-Interconnected Zones (IPSE). He worked as a Junior Researcher for Colciencias and Francisco de Paula Santander University in Cucuta, from 2017 to 2018. He is currently a Professor and researcher at Francisco de Paula Santander University. He has been a member of Applied Microelectronics Research Group (GIDMA) since January 2017. He is a professional member of the Colombian Association of Electrical, Mechanical and Allied Engineers (ACIEM) and the Institute of Electrical and Electronic Engineers (IEEE). His research interests are photovoltaic solar energy, distributed generation systems, control systems, artificial intelligence and embedded systems. 